\title{
Investigation of Fish Vision by Means of S-potential-III Photoreceptors and Spectral Sensitivity in Elasmobranchs' retinae
}

\author{
Hiroshi NIWA* and Tamotsu TAMURA* \\ (Received December 19, 1974)
}

\begin{abstract}
Two types of photoreceptors were present in both Dasyatis akajei and D. navarrae which were easily differentiated morphologically into rods and cones at the microscopic level. The lack of cones was found in another 7 species of sharks. Instead they showed exclusive domination by retinal rods.

Physiological follow-up investigations using S-potential showed that Dasyatis akajei gave the chromatic (C) response to S-potential. No trace of the C-response was observed in the retinae of four species of sharks.

From these observations the ability to discriminate color is thought to exist in the Dasyatis whereas the sharks in all probability are color blind.

All these species gave the L-response to S-potential, in which maximum wavelength was found at $494 \mathrm{~nm}$ in sharks and at $525-548 \mathrm{~nm}$ in Dasyatis. The former closely corresponds with the absorption maxima of visual pigments of shallow-sea sharks.
\end{abstract}

The function of the photoreceptors, rods and cones, is to receive light and to transmit information regarding this light to the second-order neurons. The receptors of elasmobranchs are almost exclusively dominated by the rods. And also their eyes show the peculiar structure, the tapetum lucidum: a mirror-like reflecting layer that underlies the retina. Such a structural feature may indicate that they have a minor color sense and a vision of low acuity. Some of them, however, have cones together with the rods..$^{1{ }^{27}}$ The physiological function of these cones is not yet known. Thus it is open to the question whether these cones differ functionally from the rods and play some role in their color vision.

The S-potentials discovered by Svaetichin ${ }^{3 /}$ in teleost retinae are of special interest for the investigation of color vision and spectral sensitivity of fishes. At least one of them, the chromatic (C) response, exhibits a clear dependence of the response polarity on the wavelength of the spectrum and is certainly concerned in the transmission of color signals. ${ }^{4}$

The present experiment investigates the S-potentials of elasmobranchs, sharks and rays, with special attention to color vision and spectral sensitivity. In order to determine some of the neurophysiological correlates of its retinal morphology, the photoreceptors in their retinae are also studied. Some published recordings ${ }^{5,6)}$ are reproduced in this paper for the convenience of discussion.

\footnotetext{
* Fisheries Laboratory, Faculty of Agriculture, Nagoya University. (丹羽 宏・田村 保：名古屋大学 農学部水座学教室)
} 


\section{Material and Methods}

Photoreceptors Experimental fish were hoshi-shark (Mustelus manazo), neko-shark (Heterodontus japonicus), dochi-shark (Triakis scyllia), oose (Orectolobus japonicus), akaei (Dasyatis akajei), yoshikiri-shark (Glyphis glaucus), uchiwa-shark (Discobatus sinnensis), kuroei (Dasyatis navarrae), and fujikujira (Etomopterus lucifer). The former five species were obtained from the aquarium (the Fisheries Laboratory of the University of Tokyo). The latter four species were taken in a number of ways. Three species of them, the yoshikiri-shark, the uchiwa-shark and the kuroei, were caught either with a long line or a hook, off the Hachijoh Island. The fujikujira was taken by a trawl-net off Owase Bay.

The eyes of these elasmobranchs were enucleated during the hours of darkness or during daylight. Subsequently all the enucleated eyes were treated in an essentially similar fashion; i. e., they were placed in Bouin's fluid for 1-2 hr, then anterior segment and lens were removed and the opened eye-cups were kept for at least $24 \mathrm{hrs}$ in fresh Bouin's fluid. After fixation, the retinal tissue was processed for embedding in paraffin. Routine paraffin sections of 5-6 $\mu$ thickness were prepared, some cut vertically and others tangentially to the surface of the retina. The sections were stained with Eosin-Haematoxylin.

S-potential The following five species of elasmobranchs were used: Dasyatis akajei, Heterodontus japonicus, Mustelus manazo, Triakis scyllia, and Orectolobus japonicus.

The so-called eye-cups were prepared from their enucleated eyes. The preparation was placed vitreous side upwards on filter paper soaked with Ringer's solution. A glass capillary microelectrode filled with $3 \mathrm{M} \mathrm{KCl}$ was inserted from the vitreous side in the eyecup with the aid of a micromanipulator. The indifferent one was a silver wire placed under the prepatation.

The S-potential picked up by the microelctrode was amplified with a conventional D. C. amplifier with a cathode follower input stage and displayed on a cathode ray oscilloscope.

Spectral responses were obtained by stimulating the preparation with 12 successive, nearly monochromatic light pulses of different wavelengths but of equal energy. The duration of the pulses was $250 \mathrm{msec}$ for the Dasyatis, and $1.00 \mathrm{sec}$ for the shark, since the responses of the latter were slower.

\section{Results}

Photoreceptors Two types of photoreceptors were recognized in both Dasyatis akajei and D. navarrae (Fig. 1). Fig. $1 \mathrm{~A}$ and Fig. $1 \mathrm{C}$ show a typical vertical section. The more numerous photoreceptors, considered here to be rods, were tall and cylindrical, extending from the external limiting membrane into the pigment epithelium.

In contrast to the rods, the other photoreceptors, designated here as the cones, were 


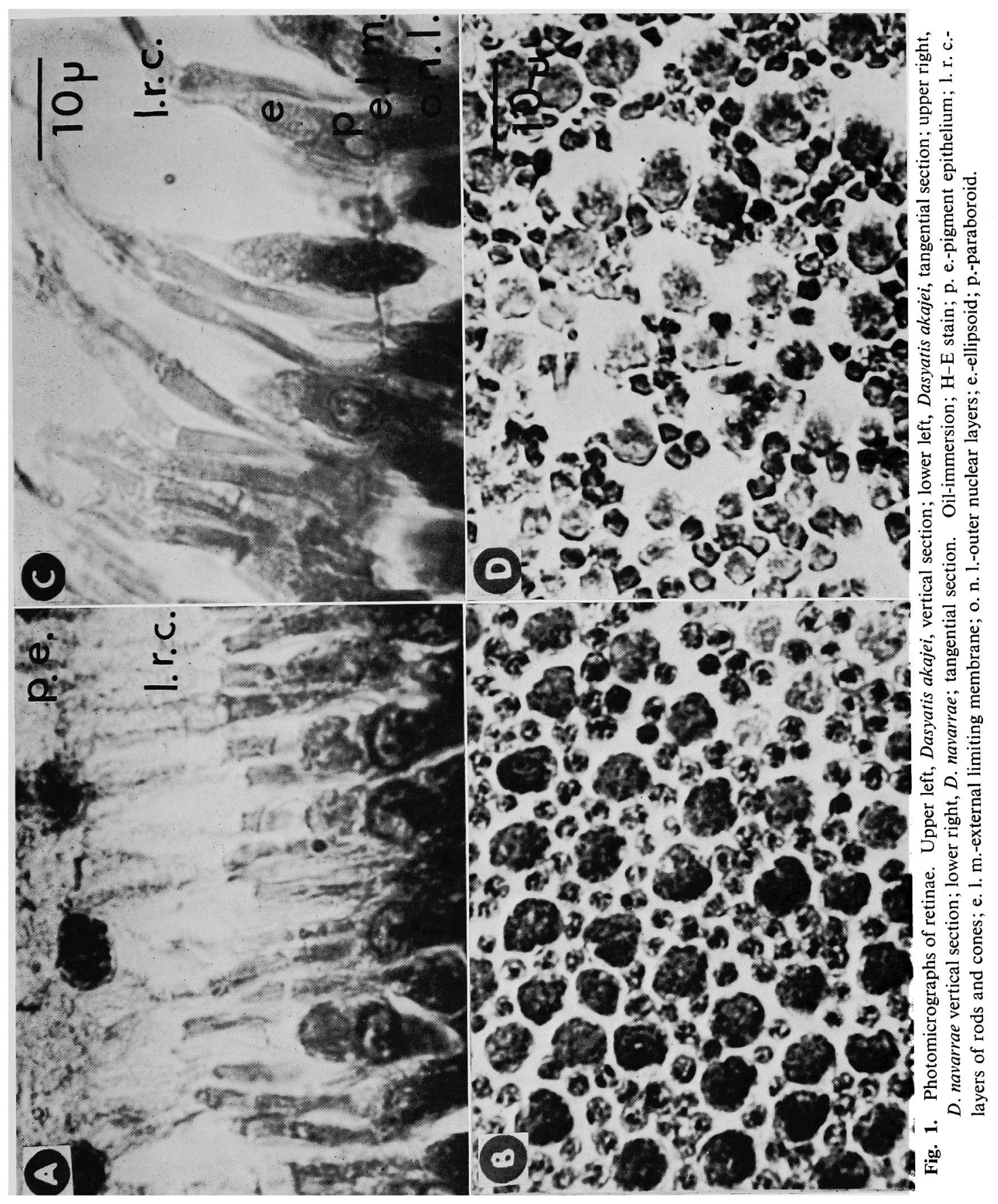




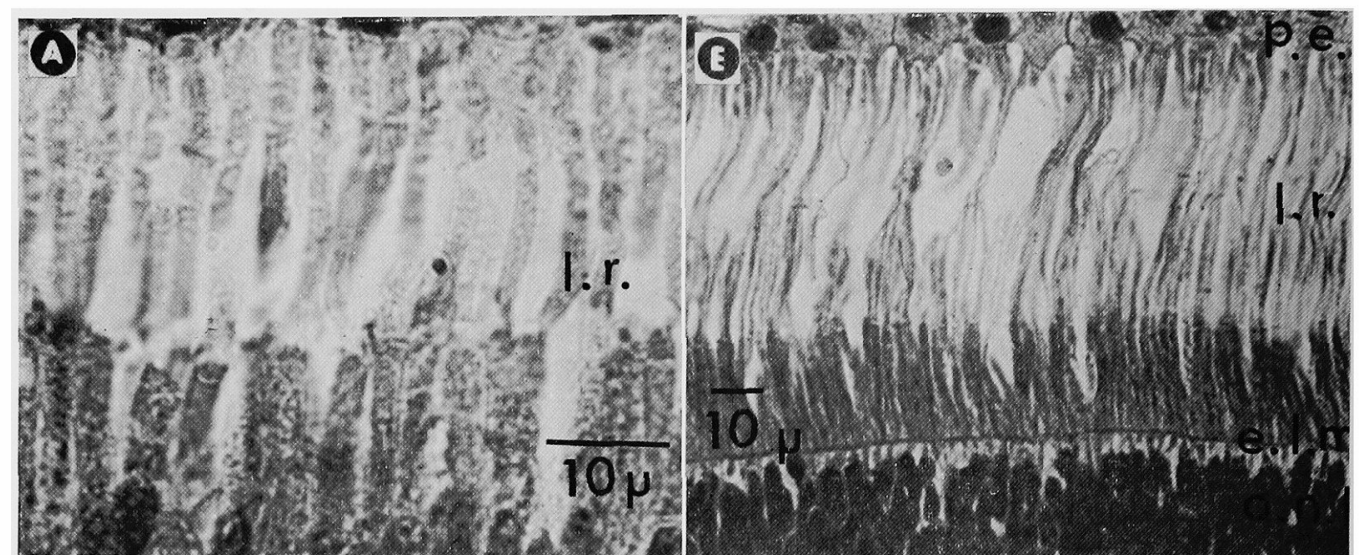

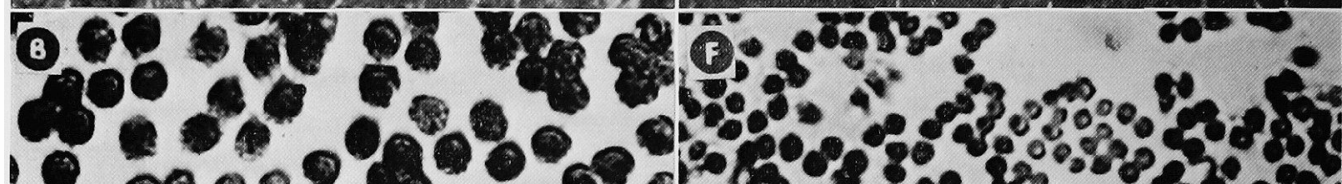

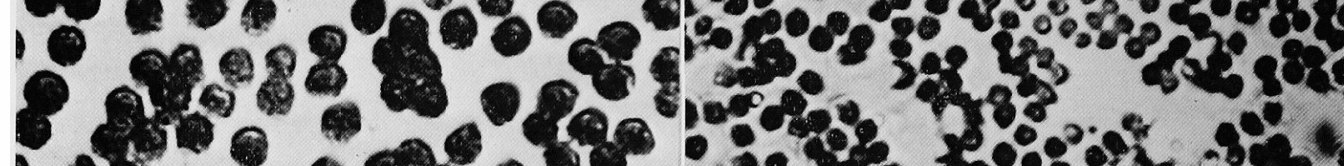

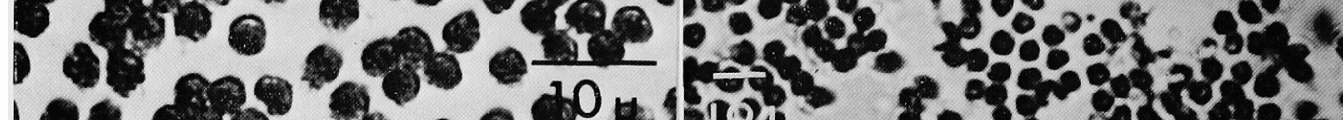

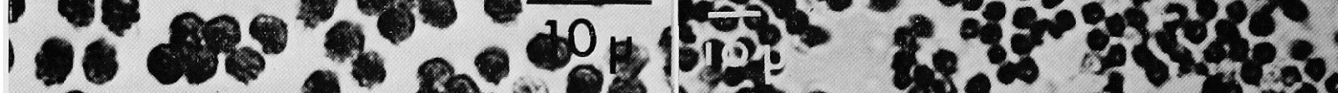

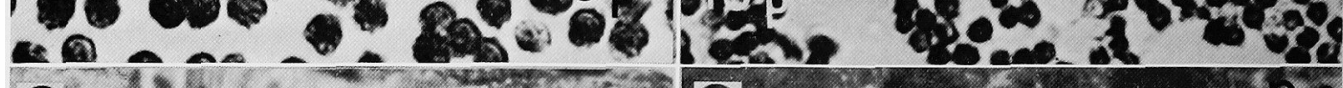
(c) 1 (1.r.

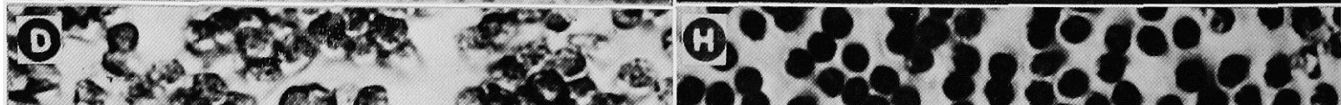

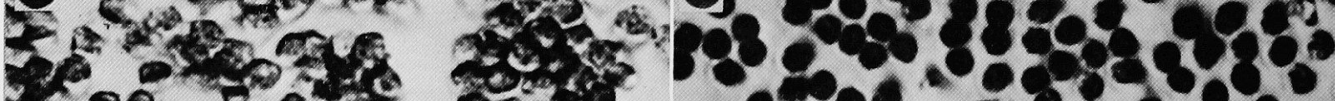

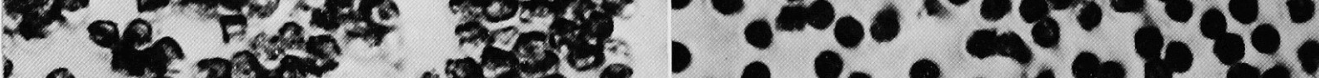

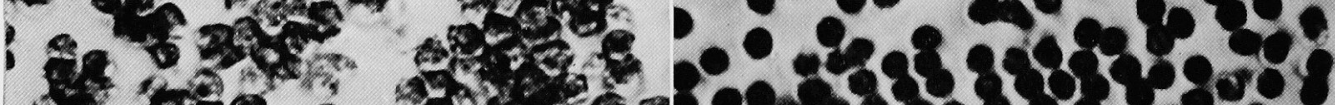

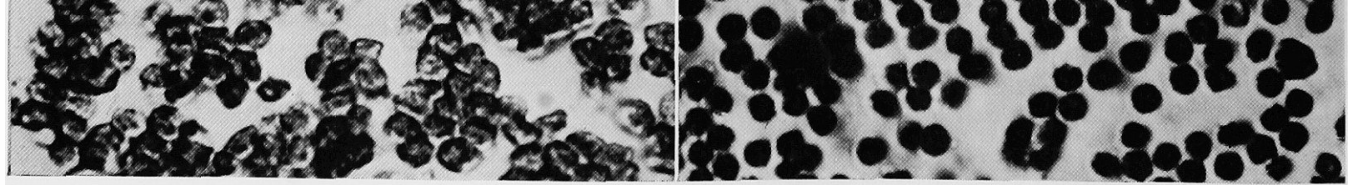

Fig. 2. Vertical and tangential sections of retinae. A, B; uchiwa-shark; C. D; fujikujira; E. F; yoshikiri-shark; G. H; dochi-shark. Oil-immersion except for yoshikiri-shark; H-E stain; p. e.-pigment epithelium; 1. r.-layers of rods. 


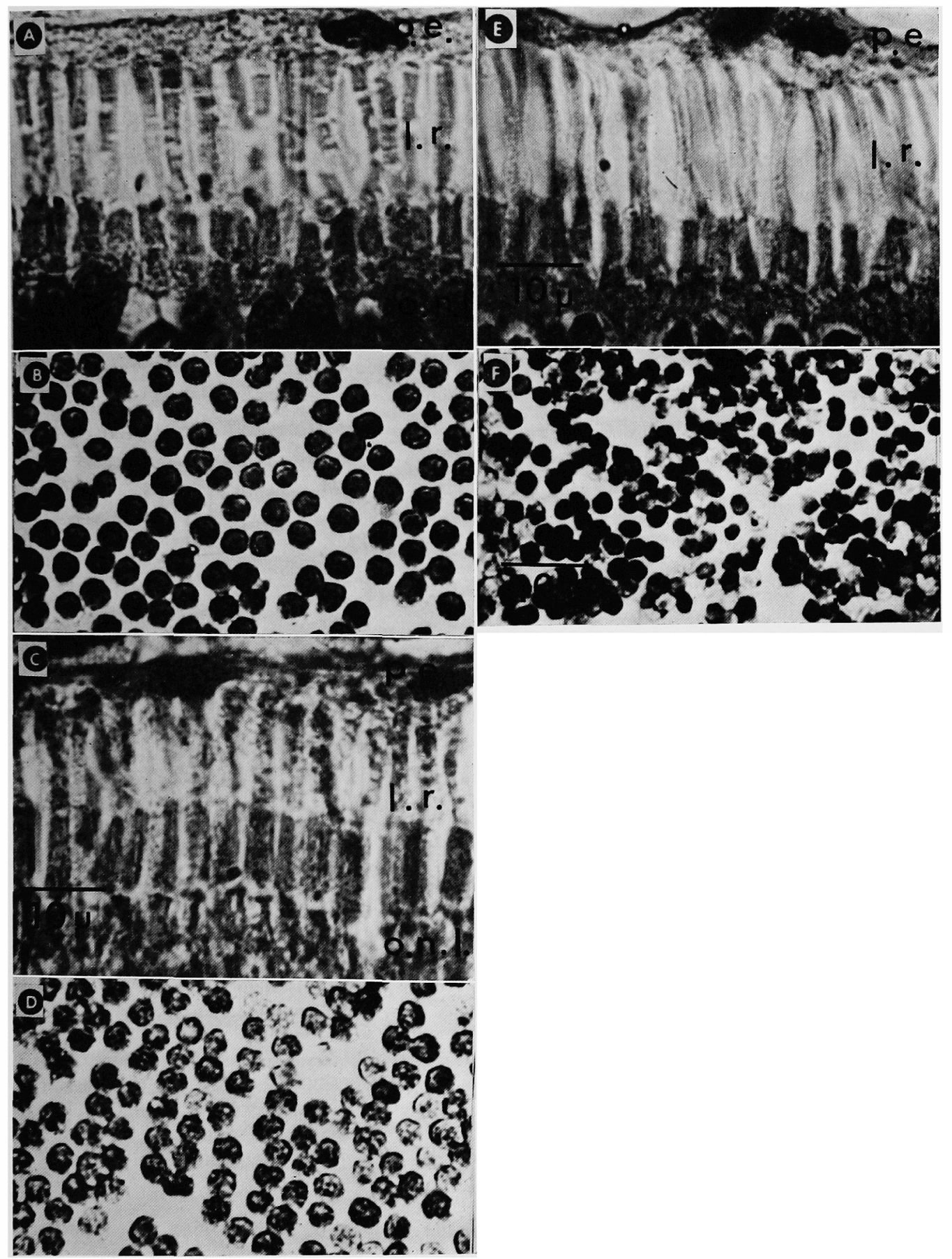

Fig. 3. Vertical and tangential sections of retinae. A, B; neko-shark; C. D; oose; E, F; hoshishark. Oil-immersion; H-E stain; p. e.-pigment epithelium; 1. r.-layer of rods. 
short and pyramidal in shape. Unlike those of rods, the tapering cone outer segments did not extend as far as the pigment epithelium. Furthermore most of the cone nuclei were situated on the receptor side of the outer limiting membrane and were thus located in the "myoid" portion of the cone. The rod nuclei were located immediately vitread of the outer limiting membrane (Fig. 1A and Fig. 1C).

A tangential section through the posterior pole of the Dasyatis retina was shown in Fig. 1B and Fig. 1D. These photographs demonstrate clearly the difference in the size and the shape of the rods and cones. The larger structures represent cross-sections of the cone ellipsoids.

The retinae of all the sharks examined are provided with only one kind of photoreceptors-rods (Fig. 2, 3). This situation was confirmed by tangential sections shown in Fig. 2 and Fig. 3. The rods of the sharks are very similar to those of the Dasyatis. Thus they are tall and cylindrical and extended into the pigment epithelial cells.

S-potential S-potentials recorded from shark's retinae were exclusively dominated by L-responses. The responses are different from chromatic (C) response, in which the positive responses are found in certain wavelengths of the spectrum (Fig. 4F). The L-response gives the negative responses through the entire wavelengths of the spectrum. The maximum of the L-response is found at about $494 \mathrm{~nm}$ in four different species of sharks (Fig. 4A-Fig. 4D).

The Dasyatis, however, gives the Cresponse as well as the L-response with a great predominance of the latter. The maximum of the L-response shifted slightly towards longer wavelengths compared with that of sharks. It appeared at around 525 $-548 \mathrm{~nm}$ (Fig. 4E).

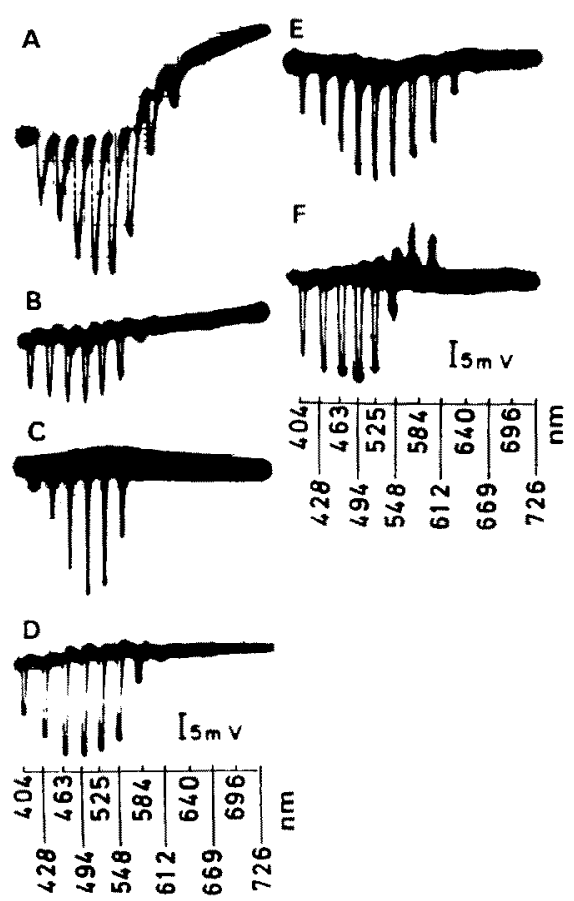

Fig. 4. Spectral responses of dochi-shark (A), oose (B), hoshi-shark (C), neko-shark (D) and sting ray (E,F). A, B, C, D, E; L-response; F, C-response.

\section{Discussion}

Most teleost fish, like most other vertebrates, possess a histologically duplex retinal system, composed of rods and cones ${ }^{T /}$ and at least the cones are subdivided into different 
varieties among those vertebrates that possess color vision. ${ }^{8)}$ The evidence for the dual visual system in elasmobranchs is by no means well established. There are conflicting reports of histological studies on the presence or absence of cones.

GRÜBER et al. ${ }^{1)}$ and HAMASAKI et al. ${ }^{2)}$ found both rods and cones in Negaprion brevirosris, while Gilbert* found only rods. Similarly, Franz ${ }^{9}$ found cones in Mustelus laevis, Neumayer ${ }^{10)}$ only rods; Kobayashi ${ }^{11)}$ found a pure rod retina in M. manazo.

$\mathrm{W}_{\mathrm{ALLS}}{ }^{12)}$ considers that the elasmobranchs' retinae are characteristically of pure rods, a point of view which has been strengthened by Gilbert's finding* that cones were absent in fifteen species of sharks. The present results also support the view expressed by WALLS ${ }^{12}$ and GILBERT*: the lack of the cones found in seven species of elasmobranchs except for two species of rays, Dasyatis akajei and D. navarrae. The contrary was claimed by GRÜBER et al. $^{13}$ and HAMASAKI et al. ${ }^{2,13)}$ These authors are of the opinion that the occurrence of cones in the retina of elasmobranchs is more common than previously supposed. Hamasaki et al. $^{13)}$ have examined 15 species of elasmobranchs from three orders and, with one exception, have found unequivocal evidence for two different types of photoreceptors-rods and cones-in the retina.

It is possible, of course, that a species difference exists in elasmobranchs with respect to the presence or absence of cones; but it is also true that some investigators mentioned above worked with the same specimens. This may be due in part to the difficulty of differentiating rods from cones at the light microscope level. In this connection, it should be noted that the morphological difference between the rods and cones may be more pronounced in some species than in others. For example, the cones are least distinct from the rods in Mustelus canis, better differentiated in $M$. mustelus, and are completely cone-like (i. e., short, with plump inner segments and small outer segments) in Myliobatis aquila. ${ }^{14}$ The cones are distinct from the rods in Ginglio burgaris, aer more so in Negaprion brevirostris and completely cone-like in Dasyatis sayi. ${ }^{2} \quad$ The presence of the cones in Dasyatis is consistent with the present observations (Fig. 1).

The Purkinje's phenomenon was observed in Dasyatis akajei by Kobayashi, ${ }^{11}$ in his ERG studies. As the phenomenon is ascribed to the duplicity of the retina viz. rods and cones, its presence in this species may indicate some differentiation present in the photoreceptors. With the same material, the C-response of the S-potential was recorded (Fig. 4). It was noticed that after stimulus of a single flash light, the time course of the S-potential was much faster in the Dasyatis than that of sharks. ${ }^{16}$. This observation is comparable to the following findings: the cone potential decays rapidly while the decay of ros potential is delayed and is very slow in cat's retinae. ${ }^{17,18)}$ A similar difference has also been observed between the single rod response in the gecko and the single cone response in the mud puppy. ${ }^{19)}$ The shorter decay time of the S-potential in Dasyatis may be mediated by the

\footnotetext{
* P. W. Gilbert: Abs. Tenth Pacific Sci. Cong. Hawaii, 176-177 (1961).
} 
scattered functional cones. These discussions lead us to conclude that the Dasyatis has color vision to some extent. Properly speaking, they represent the potentiality for color vision. There is, however, an indirect evidence against this. Hamasaki et al ${ }^{13,15)}$ in a careful study of light-and dark-adapted eyes of Dasyatis sayi, found the lack of the socalled "cone-rod break" in the dark-adaptation curves in spite of the fact that the shape of its ERG depended on whether the fish was light-or dark-adapted. Since some evidence for photopic and scotopic systems exist in this species, the smooth curves of dark adaptation may prove that the two systems change sensitivity at about same rate and that the changeover is gradual than abrupt.

The absence of cones in the shark's retinae may indicate that the potential of the sharks came from the rod systems of the retina. In addition, their retinae showed neither Purkinje's phenomenon, at least in Mustelus manazo, ${ }^{11)}$ nor C-response in four different species including $M$. manazo. Instead they are dominated by the L-response of the S-potentials having their maxima at around $494 \mathrm{~nm}$. The maximal sensitivity closely corresponds with that of scotopic spectral sensitivity curve measured by ERG recording, ${ }^{11}$ and also with the absorption maxima of visual pigments of shallow-sea sharks. The photopigment in situ was studied in Squalus acanthias and Scyliorhinus canicula By Denton and $\mathrm{Nicol}^{20}$, who placed the absorption maximum at about $500 \mathrm{~nm}$. In Squalus acanthias ${ }^{213}$ a typical rhodopsin with maximum at $500 \mathrm{~nm}$ was found by the method of extraction. In both Squalus suckleyi ${ }^{23)}$ and Mustelus californicus ${ }^{23)}$ another pigment with maximum at $497 \mathrm{~nm}$ was identified by the same method.

These observations give, therefore, presumptive evidences that sharks are color blind, a conclusion supported by behavioral experiments on other species of shark. Clark*, using the color target, concluded that a lemon shark could be conditioned to discriminate between white and red targets, and that this was probably due to the shark's ability to distiguish different degrees of brightness rather than color.

\section{Acknowledgements}

We are grateful to Dr. T. KAJIHARA and the crews of the research vessel Tanseimaru (Cruise No. KT-68-7) belonging to the Ocean Research Institute of the University of Tokyo for their enthusiastic cooperation of the collection of several kinds of elasmobranchs.

\section{References}

1) S. H. Grüber, D. I. Hamasaki, and C. D. B. Bridges: Vision Res., 3, 397-399 (1963).

2) D. I. HAMASAKI and S. H. Grüber: Bull. Mar. Sci., 15, 1051-1059 (1965).

3) G. SVAETiCHIN: Acta physiol. scand., 29, Suppl. 106, 565-600 (1953).

4) E. J. MacMichol, Jr and G. Svaetichin: Amer. J. Opthal., 46, Part II, 26-40 (1958).

5) T. Tamura, I. Hanyu, and H. Niwa: This Bull., 32, 260-261 (1966).

\footnotetext{
* E. Clark: Abs. Tenth Pacific Cong. Hawaii, 176-177 (1961).
} 
6) T. TAmura and H. Niwa: Comp. Biochem. Physiol., 22, 745-754 (1967).

7) W. Wunder: Z. vergl. Physiol., 3, 1-61 (1925).

8) W. B. Marks: J. Physiol., 178, 14-32 (1965).

9) V. Franz: Zoll. Jahrb., Abt. f. allg. Zool. u. Physiol. d. Tiere, 49, 232-462 (1931).

10) L. Neumayer: Arch. mikrosk. Anat. Entwz Mech., 48, 83-111 (1896).

11) H. Kobayashi: J. Shimonoseki Coll. Fish., 11, 407-538 (1962).

12) G. L. WALIS: In "The vertebrate eye and its adaptive radiation", Cranbrook Press, Michigan, 563569 (1942).

13) D. I. Hamasaki, C. D. B. Bridges, and K. A. MeneghinI: In "Sharks, Skates, and Rays", the Johns Hopkins Press, Baltimore, 447-463 (1967).

14) M. L. Verrier: Sci. Nat. Zool., 18, 205-216 (1935).

15) D. I. Hamasaki and C. D. B. BRIDGes: Vision Res., 5, 483-496 (1965).

16) H. Niwa and T. Tamura: This Bull., 33, $91-97$ (1967).

17) K. T. Brown, K. Watanabe and M. Murakami: Cold Spring Harbor Symp.quant. Biol, 30, 457482 (1965).

18) K. T. Brown and M. Murakami: Vision Res., 8, 1145-1171 (1968).

19) J. ToYota, H. Nosaki, and T. Tomita: ibid., 9, 453-463 (1969).

20) E. J. Denton and J. A. C. Nicol: J. mar. biol. Ass. U. K., 44, 219-258 (1964).

21) G. WALD: J. Gen. Physiol., 22, 391-415 (1939).

22) D. D. BeAtTY: Nature, 222, 285 (1969),

23) F. Crescitelli: In "the Handbook of Sensory Physiology" (Ed. by H. J. A. Dartnall) Springverlag, 1972, 245-363. 